\title{
Flexible Learning: The Design Thinking Process as a K-12 Educational Tool
}

\author{
Katia Caetano Lord \\ Georgia State University
}

Flexible Learning is a personal investigation of the relationship between the design-thinking process and standardized primary and secondary education. The problem-solving methods used in graphic design are studied as a means of enhancing skills among K-12 students in the education system-skills that are not generally being developed, some of which are creativity, engagement, collaboration, evaluation, refinement, and presentation techniques. I will explain how the creative application of the design-thinking process in the classroom, usually in the form of a project, can expand the horizons for whole-brain and creative thinking among students.

Keywords: Collaboration, Creativity, Critical Thinking, Design Thinking Process, Education Reform, Engagement, Evaluation, Graphic Design, Presentation Techniques, Problem Solving, Refinement, Standards, Whole-Brain Thinking

\section{INTRODUCTION}

Flexible learning is a personal investigation of the relationship between the problem-solving methods of the design-thinking process, and skills enhancement within standardized primary and secondary education. The design-thinking process, which I define as a series of operations leading to a solution or serving as a bridge from research to synthesis, serves me well as a visual problem-solver. As an educator, it was a natural step to show how it could foster creative and critical thinking within the standardized curriculum currently being offered to primary and secondary education students. This article addresses the design-thinking process as a possible solution to a problem. It defines the design-thinking process and provides guidelines to illustrate the process in the classroom. It describes the connection between the design-thinking process and education.

\section{DESIGN-THINKING PROCESS ENHANCES WHOLE-BRAIN THINKING}

Graphic design is essentially visual communication, not just any communication. It is specific; it has a purpose; and it values the audience's response to a given message. It presents a problem one must research, understand, and solve. In fine arts, the work of art typically stems from a view, opinion, or feeling from the artist. The viewers relate to it, learn from it, or may be inspired by it. However, in graphic design, the designer communicates something that already exists for a purpose such as a message, an image, an idea or an action. The purpose is to motivate viewers or audiences to buy a product, use a service, learn certain information, etc. When the message is effectively communicated, it motivates consumers, or viewers, to carry out the intended task, that is, the purpose of the design. 
I believe that graphic design offers powerful effects because it follows the design-thinking process. As a designer, I follow such the design-thinking process, steps in which I research, analyze, think, create, produce, and present a solution. These steps help me understand a concept, think creatively, and target my audience. I have defined the design-thinking process as a series of operations that will lead to a solution or a bridge from research to synthesis. The design-thinking process is the methodology, which utilizes a problem-solving protocol. Also, the design-thinking process combines left (cognitive and intellectual) and right brain (rational and emotional) thinking. Thus, the design-thinking process enhances whole-brain thinking.

In exploring the connection between education and the design-thinking process, the question arose as to how the design-thinking process could affect students' creative freedom while they are learning and understanding a new concept. Realizing a design-thinking process could be implemented as a tool in the education system as a means of introducing a new way of fostering creative thinking within the curriculum currently offered to students, it also became apparent the design-thinking process could transcend from the corporate world as well as the graphic design world and be used in the education system, regardless of subject matter or grade level. Thus, the design-thinking process offers a platform for creativity, critical thinking, comprehension, interaction, collaboration, management techniques, decisionmaking skills and media literacy knowledge.

\section{ADAPTATION TO SHIFTS, STANDARDIZED EDUCATION, AND THE DESIGN-THINKING PROCESS}

The speed in which technology is being developed and its availability to the public allows for worldwide communication exchange. Bypassing traditional media (TV and newspapers) in the shift to social media (blogs, YouTube, Facebook, etc.), it allows ordinary citizens to have a voice. History is filled with shifts in society and technology. Similar transitions happened in the 1500 s with the rise of printing technology, which created conditions wherein information was available to a broader reading public, allowing for an increase in literacy and thus of individual opinions and thoughts.

Society adapts, sometimes, by adjusting to the social and technology shifts. We must continue to adapt to such shifts, but we must also harmonize education with these developments, as standards have also changed. These shifts in standards and technology have also promoted an unconscious design awareness, suggesting a preference for aesthetically-designed products, user-friendly interfaces, and simple messages that are easy to understand. As in previous ages, people in the 21 st century are demanding complex and creative solutions to issues such as social and technological shifts. The designthinking process is beneficial in order to adjust or adapt to the social, technical, historical, political, etc. shifts. This unconscious design-awareness preference is evident in the major innovative companies of the 21 st century such as Apple, Amazon, Google, Starbucks, and many others. The worldwide success of such innovative companies reinforces the need for skills such as creativity, critical thinking, innovation, media literacy, etc. I believe these aforementioned skills as well as the design-thinking process should be incorporated into the education systems, not only to promote innovative thinkers, but also to integrate change and offer future solutions to existing and potential problems.

In education, teachers have the responsibility to "adequately prepare students for an era of change, information, and knowledge explosion in the 21st century" (Clayton-Pedersen and O'Neill, sec. 4, para. $3)$. Hence, education reform is in order such as utilizing and implementing the design-thinking process to better prepare students. Education reform is not new and it has been discussed at many academic, economic, and social levels. My intent is not to repeat what has been said, but to propose the idea that standardization in education can be complemented with the design-thinking process to stimulate and encourage students to develop skills such as observation, questioning, collaboration, experimentation and critical thinking. As a graphic designer and creative thinker, I am not addressing the entirety of education reform. I am simply speculating that the design-thinking process could be used as an educational tool in addition to also providing students with an understanding of media literacy and stimulating young minds to inquire and think critically. When given a chance to think, observe, analyze and create, a student can do 
a lot more than to only to simply learn a concept. They can understand a concept, synthesize it and take it to the next level.

Currently, standardized testing can force learning to be general, linear and repetitive. As a result, standardized testing can stagnate individual thinking and creative discovery. My belief is that both teachers and students must adapt to changes within the education system. We can adapt by utilizing the design-thinking process used as an educational tool to proliferate thinking and innovation. Standardized education is a problem to be solved and I believe that the design-thinking process presents a solution to real-world problems. Education must continuously restructure information to provide our students with a chance to compete in the real-world and on a global-level. If students are exposed to the design-thinking process, this will allow them to be better prepared to compete with real-world application and, eventually, in the job market. "Students learn more deeply if they have engaged in activities that require applying classroom-gathered knowledge to real-world problems" (Barron and Darling-Hammond, 2008, sec. 1, para. 2). Thus, I believe that we can alter the education system for the better by utilizing and implementing the design-thinking process.

\section{DESIGN-THINKING PROCESS AS A POSSIBLE SOLUTION TO A PROBLEM}

The design-thinking process presents a possible solution to a problem. The design-thinking process is a series of operations that can lead to a solution or a bridge from research to synthesis. Many businesses and graphic design companies utilize the design-thinking process as an organizational plan to deal with processing and categorizing information. Furthermore, the design-thinking process offers a platform for understanding, creativity, critical thinking, interaction, collaboration, management techniques, decisionmaking skills, and media literacy.

Design thinking is a methodology for practical, creative resolution of problems or issues where many look for an improved future result. In the design-thinking process, the steps may sometimes overlap each other. They may also not follow a linear format, but an organic arrangement. I use each step as an attempt to get to the next step. Sometimes, whenever I feel stuck or cannot move forward, I skip certain steps. Oftentimes, I also have to go backwards or even start completely over in order to move forward. The design-thinking process is flexible based on the individuals' needs, goals, and objectives. Moreover, "Design thinking is above all an iterative process, with constant improvement - experimenting with and then scrapping Plan A and moving onto Plan B - as a central tenet" (Gow, 2012, para. 4)

Although the steps within the design-thinking process do not necessarily always follow consecutively, I will list them below in a linear format. My standard design-thinking process is usually composed of the following eight steps:

1. Identify: First, I identify the problem I must solve.

2. Research: I breakdown the problem into parts and research each part. I gather facts, opinions and organize my information. I make sure that I am looking at that problem from different angles, especially from an "audience" perspective. After my research, I fully understand my problem.

3. Define: Because I understand the problem, I now define goals and objectives for finding a solution. I define the essence of the solution.

4. Create/Ideate: I generate strategies to reach my goal. I make lists, brainstorm, question, and try different approaches using various methods, such as rearrange, reverse, combine, distort, rotate, repeat, eliminate, magnify, use analogies or metaphors, compose, harmonize, contrast, balance, order, unify, brainstorm, consult the internet or library, use my experience, etc. I construct mood boards and create thumbnails, using elements and principles of design. I think of details that could enhance my solution.

5. Select: In this step, I review my problem along with my research. I reflect on the solution essence I have defined and correlate that with the possible solutions I created. I refine favorite ideas and decide which solutions will better attract the audience. 
6. Implement: Here is where I turn the idea into reality by first establishing the output and production mode. During production, all refinements are done (details, spell check, color, format). I take great care in craftsmanship and use the most appropriate mode of presentation established by the relationship between the problem, the solution, and the audience/client.

7. Evaluate: Once the presentation is over, I evaluate my results, accounting for audience response, self-criticism, goal achievements, and unforeseen problems. (Measurements are established for some projects, but this depends on the nature of the project itself).

8. Refine: On certain occasions, solutions must be refined even further. Here is where the process could start over and help direct the advancement of an idea.

FIGURE 1

\section{DESIGN-THINKING PROCESS}

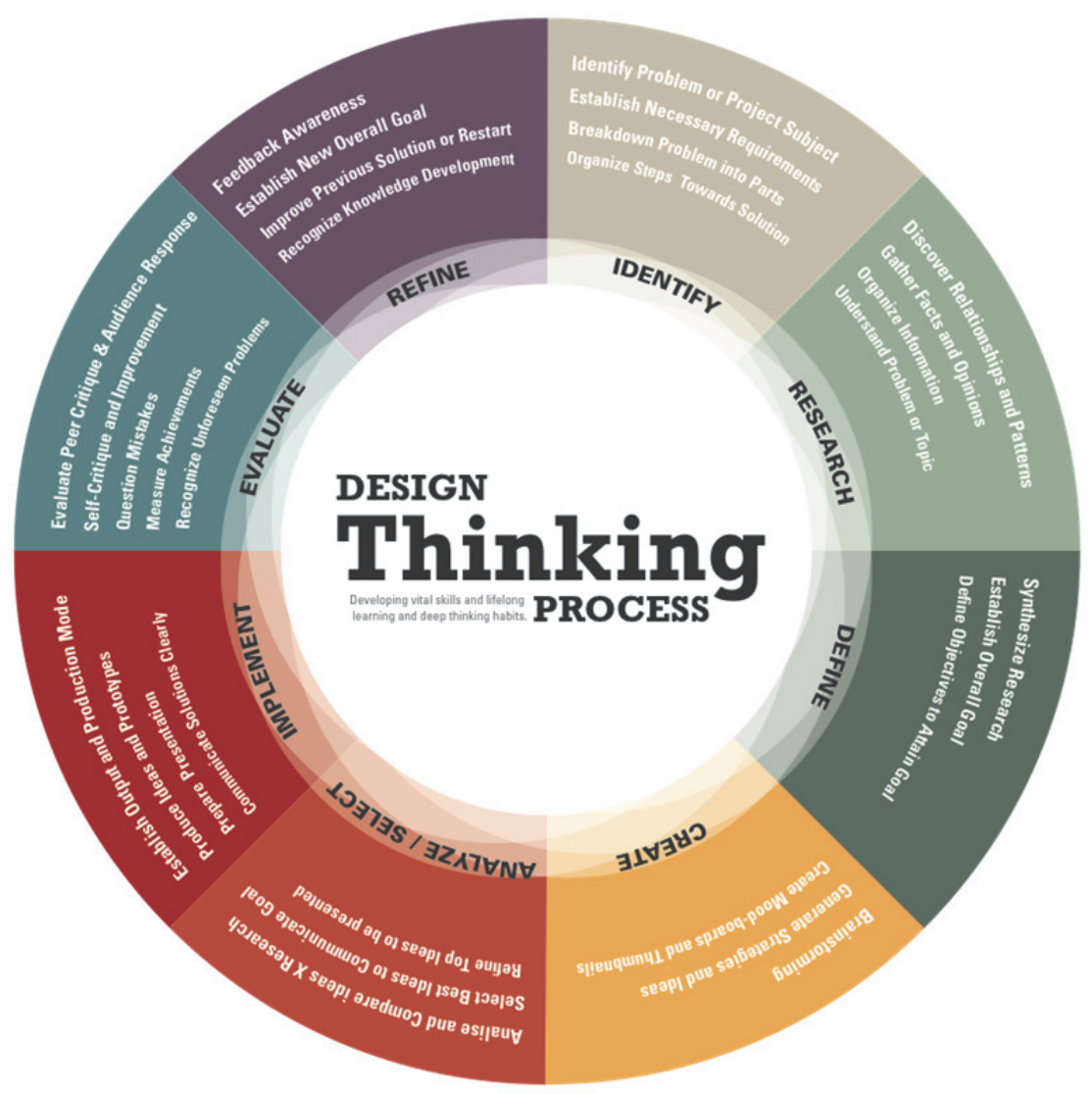

\section{THE CONNECTION BETWEEN THE DESIGN-THINKING PROCESS AND EDUCATION}

The design-thinking process offers a platform for creativity, critical thinking, interaction, and collaboration. The design-thinking process promotes understanding of a problem or matter and the development of management techniques, decision-making skills, and media literacy knowledge. In using the design-thinking process and its steps to understand a problem, set goals or intentions, and analyze alternative solutions, it serves as an organizational plan for providing information for both students and teachers. I believe the design-thinking process would be invaluable as a tool in all educational settings. I believe that design-thinking is a system that can be incorporated into current educational strategies. In current public school classrooms, students do not always have the opportunity to fully comprehend any 
given topic. Teachers must follow a scheduled curriculum and move onto other lessons, regardless of whether or not students fully grasped the precedent subject matter.

Thus, the design-thinking process allows understanding of a problem or topic in its full context. Full comprehension can be achieved by applying the design-thinking process, which requires skills such as articulation of problem and solution, presentation, clarity, collaboration, analysis, management, decisionmaking and interaction-all skills that are necessary in the education system. The power of doing is facilitated by the design-thinking process because it involves learning experiences where students are engaged in creating their own solutions or gaining insights to a topic, instead of simply being receivers of information. The design-thinking process would allow for students with different styles of learning and different abilities to succeed academically because the process takes learners' interests into account. For instance, audio-visual learners can watch educational videos in order to gain a better understanding of concepts. The design-thinking process also promotes media literacy awareness through research, production management, and analysis of presentation platforms.

In the previous section, I highlighted the steps of the design-thinking process as well as include Figure 1. The steps of the design-thinking process promotes thinking and planning throughout the research phase. Cognitive or active participation is implemented through the brainstorming and production steps. Social interaction is achieved with others through the presentation and analysis steps. Social interaction is oftentimes accomplished with group projects. The design-thinking process features interaction with peers and is an advantage to the learning environment as well as part of self-growth and global understanding. There are “....widespread benefits of cooperative learning, in which small teams of students use a variety of activities to more deeply understand a subject. Each member is responsible not only for learning what is taught but also for helping his or her teammates learn, so the group become a supportive learning environment" (Barron and Darling-Hammond, 2008, sec. 1, para. 4). The good news is that the design-thinking process can be applied to individual and group projects. It is versatile. It is beneficial. The design-thinking process is flexible and useable by both students and teachers.

With the design-thinking process, it makes it easier for teachers to constantly recreate the instructional process based on students' different needs and learning styles. "It falls upon the teacher to constantly recreate the instructional process and offer a variety of choices for approaching information and tasks in order to meet learners' ever changing, individual needs" (Smith, 1997, para. 4). In addition to the individuals' learning styles, successful learning, task completion, and problem-solving depend on the implementation of a variety of learning strategies such as active participation and social interaction strategies as mentioned. Overall, I believe that teachers should encourage students to actively participate in classrooms utilizing the design-thinking process rather than being passive receivers of information.

I believe that the design-thinking process would allow students to learn within their own style by choosing a written, graphic or multimedia output, developing an inquisitive mind through research, and defining a plan of action from idea to delivery. To perform the necessary tasks, students would be expected to draw from knowledge bases in order to integrate them and analyze them. I believe that the design-thinking process could be used as a teaching strategy in most, if not all, school subjects. This strategy of using the design-thinking process as an educational tool, could not only engage students' interests more actively, but also allow for better communication integration and problem solving for situations encountered in the real-world such as working in (and adapting) to an unknown environment. The design-learning process could yield new knowledge and shift minds to emphasize exploration and discovery, design and development, self-growth and evaluation.

One of the main challenges that the design-thinking process faces is that it is not to be confused with project-based learning (PBL). It is essential to differentiate and acknowledge these differences. The first major difference is "A PBL project tends to explore a relatively narrow subject area, with a narrow essential question...In Design Thinking, the goal is to explore the widest possible area(s) for longer, to offer a good half-dozen or more potential lines of enquiry that students might end up exploring" (McIntosh, 2012, para. 7). The second major difference is "In Design Thinking, the students, not the teacher, write the essential questions...the teacher avoids asking a question at all. In PBL, the teacher narrows down a large, potential area of study and narrows it down into a manageable project question" 
(McIntosh, 2012, para. 9-10). The third difference is "The ideas of what students will produce in PBL are set by the teacher...In design thinking, the decision about which medium to use to show an idea lies entirely with the students" (McIntosh, 2012, para. 13-14). The fourth difference is "Design thinking provides a set of vocabulary that increasingly makes sense to employers in the creative, financial and governmental and innovation sectors... The language PBL uses is, by contrast, inconsistent and not usable outside the classroom" (McIntosh, 2012, para. 15-16). Overall, using the design-thinking process encourages "deeper, wider thinking and helps develop a life skill provides great value to learners" (McIntosh, 2012, para. 16). Thus, the benefits of the design-thinking process can, at most times, outweigh PBL. I believe that the design-thinking process will be more beneficial to students and allow students to become more marketable to potential employers.

\section{IMPLEMENTING THE DESIGN THINKING PROCESS IN PRIMARY AND SECONDARY EDUCATION}

The steps below are offered as a guideline for teachers and students in order to systematically and visually demonstrate the relationship of the design-thinking process and primary and secondary education methods. Because I believe in the organic nature of the design-thinking process, the guideline is simply a suggestion on how to begin implementing the design-thinking process into the primary and secondary education system.

Each step offers possibilities for students to develop skills, such as creativity, critical thinking, responsibility, leadership, engagement, collaboration, evaluation, refinement and presentation techniques for use inside and outside the classroom. Steps can be skipped or repeated to suit specific challenges:

1. Identify: Students must identify the new subject to be researched and understood or identify the problem posed. This information needs to come with certain expectations and parameters by individual teachers.

2. Research: Either give students specific topics to be researched or let them decide the research topic within a given subject.

3. Define: Students must define what they understand about the topic or problem in a short, one paragraph statement. This is a step where teachers can measure the effort each student has given to research and either ask for more information or give permission for the student to go to the next step.

4. Create/Ideate: This step is where students use their creativity, either by creating possible solutions or by thinking of creative ways to present information.

5. Select: Here students will select their best idea/solution and, once again, get approval from teachers to go onto the implementation step. Teachers could give students advice on what they expect the student to present.

6. Implement: It's the students' choice and responsibility to choose a production mode that will best suit their abilities and best conform to their goals. Here students will present their solution or knowledge to the classroom or student body.

7. Evaluate: Classroom or peer critique is important here, along with teacher feedback and measurement of expectations. Failure is also a learning experience.

8. Refine: Because schools are a learning environment, students could/should be given a choice to refine their solutions/presentations for a deeper understanding. With the opportunity to refine, students can achieve improvement and even brilliance. 
FIGURE 2

DESIGN-THINKING PROCESS AS AN EDUCATIONAL TOOL

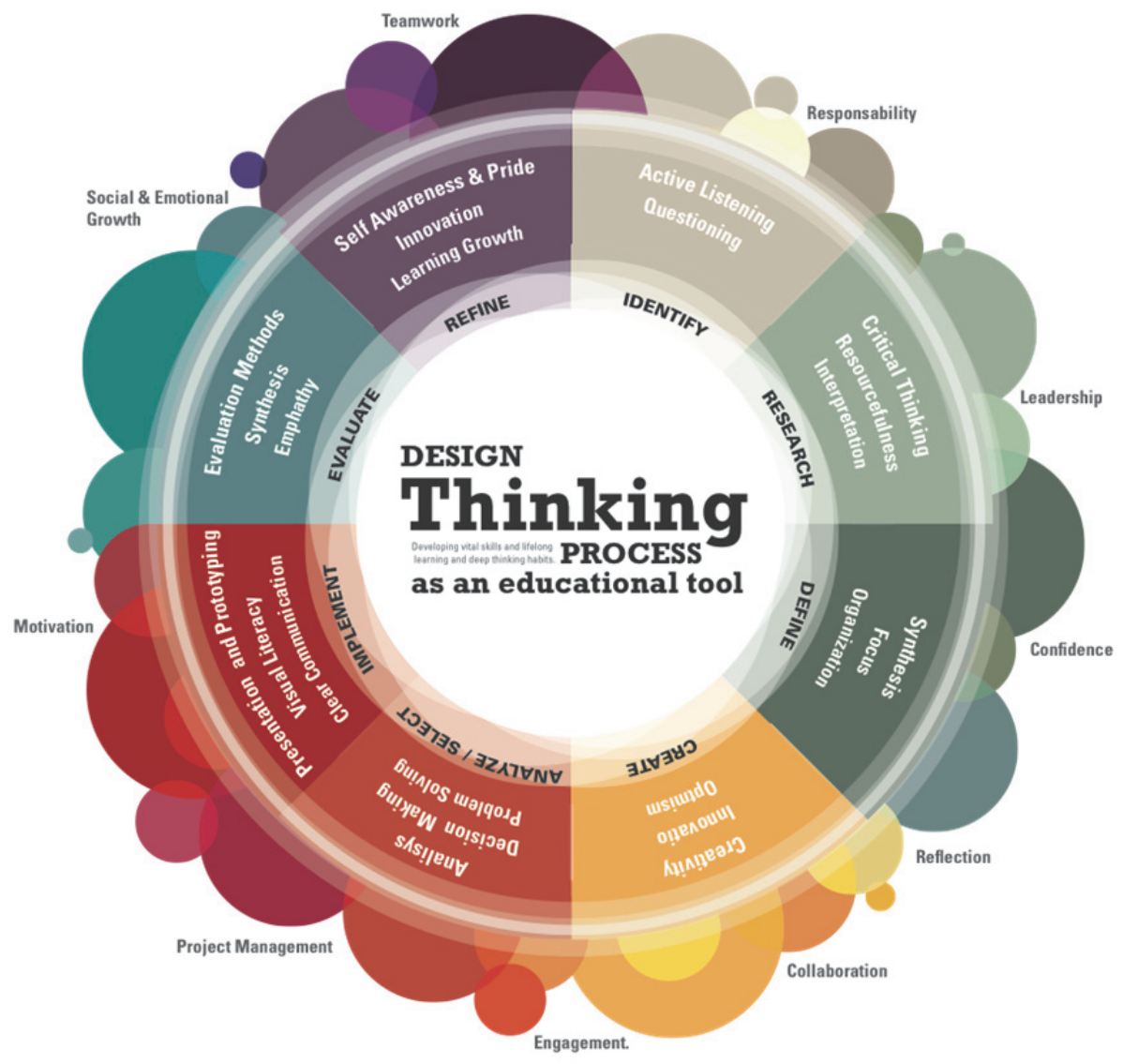

\section{CONCLUSION}

The design-thinking process enhances vital skills, whether it is used in the graphic design field, corporate world, or in the classroom. Using the design-thinking process as an educational tool in the classroom, will enhance students' skills such as creativity, engagement, collaboration, evaluation, refinement, and presentation techniques. The design-thinking process can also better prepare students for the jobs that will exist in the future by giving them the ability they need to be adaptable and creative. Developing a whole-brain learning approach to education can only increase productivity on a global level. The design-thinking process could certainly give many the upper hand when trying to find solutions to the global problems facing us today. As shown in the figures (Figure 1 and Figure 2) featured in my article, it is possible to insert the design-thinking process into the education system. In order for the design-thinking process to be successful in the education system, support from administrators and dedicated teachers to implement the design-thinking process is necessary. The educator's mentality must be one of guide and not simply expert and information-giver. In conclusion, I would use the design-thinking process as a lifelong learning and educational tool. 


\section{REFERENCES}

Barron, B., \& Darling-Hammond, L. (2008). Powerful Learning: Studies Show Deep Understanding Derives from Collaborative Methods. Edutopia. Retrieved August 22, 2018, from https://www.edutopia.org/inquiry-project-learning-research.

Clayton-Pedersen, A., \& O’Neill, N. (2005). Curricula Designed to Meet 21st-Century Expectation. Educause. Retrieved August 24, 2018, from https:/www.educause.edu/research-andpublications/books/educating-net-generation/curricula-designed-meet-21st-century-expectations.

Gow, P. (2012). An Experience of 'Yes'. National Association of Independent Schools. Retrieved August 26, 2018, from https://www.nais.org/magazine/independent-school/spring-2012/an-experienceof-yes.

McIntosh, E. (2012). What's the Difference between PBL and Design Thinking? Ewan McIntosh and NoTosh Limited. Retrieved August 28, 2018, from http://edu.blogs.com/edublogs/2012/08/whatsthe-difference-between-pbl-and-design-thinking.html.

Smith, K. L. (1997). Preparing Faculty for Instructional Technology: From Education to Development to Creative Independence. Educause. Retrieved August 30, 2018, from https://www.educause.edu/ir/library/html/cem/cem97/cem9739.html 